\title{
Corrosion Behavior of Copper-Steel Particulate Composite
}

\author{
J. T. AL-Haidary (Corresponding author) \\ Production Engineering and Metallurgy, University of Technology \\ P. O. Box (35010) - Baghdad- Iraq \\ Tel: 964-77-00741979 E-mail: jalhaidry@yahoo.com \\ Emad S. AL-Hassani \\ Materials Engineering, University of Technology \\ P. O. Box (35010) - Baghdad- Iraq \\ Tel: 964-77-0252-4446 E-mail: emad2000x@yahoo.com
}

\author{
Sheelan R. Areef \\ Applied Science, University of Technology, Iraq \\ E-mail: sheelanrafeeq@yahoo.com
}

Received: February 24, 2011

Accepted: April 6, 2011

doi:10.5539/mas.v5n3p234

\begin{abstract}
This work was conducted to study the corrosion behavior of the steel particle reinforced copper matrix composites, under different conditions; namely heat treatment, concentration of corrosion media, and different weight percent of steel particles.

The density, corrosion rate, micro-structure, and Vickers micro-hardness, were investigated. The results showed that composites with limited steel particle contents can be used. The microstructure of the composites showed severe corrosion of the steel particles especially in the low steel particle content ones, which gave an effect more or less similar to the pitting corrosion. The Vickers micro-hardness showed a development in the hardness of the different zones of the composite due to the effect of the cold working and subsequent annealing, but yet with the same marked increment in micro-hardness at the particle-matrix interface. The later gave a strong indication that diffusion was taken place. Corrosion rate increased with increasing steel particle contents, because of severity corrosion in steel particles.
\end{abstract}

Keywords: Metal matrix composite, Heat treatment, Corrosion, Potentiostat polarization

\section{Introduction}

Metal matrix composites are materials with metals as a base and distinct, typically ceramic phases added to improve the properties. Although it is desired that these phases remain distinct and separate, reactions do occur between them. If this is the case, it affects the processing and final properties of the composites, regardless of which type of reinforcement is used (ASM Handbook. 2001). Reinforcement types include laminations, continuous fibers, discontinuous fibers, whiskers and particles of different morphologies are used. Each of these reinforcements affects the base metal in different subtle ways, but composites generally show improvement over the monolithic metal in, at least, one of the following properties: yield strength, hardness, tensile strength, wear resistance, coefficient of thermal expansion etc. Properties that depend on the system include thermal and electrical conductivities (William D. Callister, Jr. 2007). While metal matrix composites show great potential in these areas, they have only found limited use in actual industrial applications. Continuous fiber composites have been especially restrained, finding use only in high value parts in the aerospace field. This is due to the difficulty in processing of the materials, forcing manufacturers to offer them at high cost (Hatta, H., Aoi, T., Kawahara, I. and Kogo, Y. 2004). Discontinuous metal matrix composites, isotropic in nature, have more options and ease of preparation than continuously reinforced types, so that cost is lowered and acceptance is wider. However, even these materials are limited to a few industrial applications. For particle reinforced copper matrix composites, the main current commercial processing is done using the powder metallurgy technique i.e. mixing, compacting and 
sintering. While this method has the advantage of controlling the volume fraction of the constituents it also has many drawbacks. These include tendency to segregate due to the difference in the atomic weight, particles desire to clump with each other, shrinkage and increased void formation. These all lead to higher cost (Pranav K. Deshpande, 2006).

$\mathrm{Cu}-\mathrm{Fe}$ alloys are materials that are more and more extensively applied in industry. Firstly, they are utilized as master alloys to produce new copper alloys for very special purposes. They are used as materials for electrical device components, for example, semiconductor lead frames, electrical connectors, and electrical fuses. The phase diagram of the $\mathrm{Cu}-\mathrm{Fe}$ system shows that copper solubility in iron is practically high at high temperatures. However, in the range of low temperatures, the copper solubility significantly drops to 1.88 at. $\%$ at the eutectoid temperature of $850 \mathrm{oC}$. A new melting process has been used to prepare $\mathrm{Cu}-\mathrm{Fe}$ alloys with 10,20 , and $30 \mathrm{wt} \%$ $\mathrm{Fe}$, but these alloys show a tendency to segregate. On determining and applying the proper parameters of the melting process, it is possible to produce $\mathrm{Cu}-\mathrm{Fe}$ alloys with such high iron content (Z. J. Zhou, Y. S. Kwon, 2005).

Studies of the corrosion behavior of $\mathrm{Cu}-\mathrm{Fe}$ alloys in aqueous media seem to be rare. It has been reported that iron-alloying addition to copper alloys may be used to improve their corrosion resistance. The mechanisms of the dissolution and passivation of bulk polycrystalline icosahedra Al63Cu25Fe12 specimens during electrolytic corrosion in sodium hydroxide and sulfuric acid solutions were studied by El-Egamy(S.S. El-Egamy, 2008). He found that selective dissolution of $\mathrm{Al}$ and $\mathrm{Fe}$ from the alloy surface occured at the open-circuit potential, which leads to precipitation of porous layer of re-crystallized copper. After anodic polarization, the dissolution of the alloy is followed by re-deposition of $\mathrm{Cu}$ and formation of $\mathrm{Cu} 2 \mathrm{O}$ (S.S. El-Egamy, 2008).

\section{Experimental}

The experimental procedures include heat treatment, corrosion test, scanning electron microscopy and finally hardness test. The composites consist of pure copper containing $99.99 \% \mathrm{Cu}$ as a matrix and steel particles with chemical composition shown in Table (1) as a reinforcements phase. The steel particle reinforced copper matrix composite was prepared by stir casting processing method (Feras M.A. Kafiah, 2007). These composites contained different weight percent of steel particles, namely $10 \% \mathrm{wt}, 20 \% \mathrm{wt}, 30 \% \mathrm{wt}, 40 \% \mathrm{wt}$ and $50 \% \mathrm{wt}$ (table 2).

In this project the specimens were cold worked using a cold-Rolling process. It is noticed that the percentage amount of deformation decreases with increasing the $\mathrm{wt} \%$ of steel particles as shown in Fig. (1).

Six cold rolled strips were produced; the maximum amount of cold working was different for each composite depending upon the appearing of the cracks on the surface. Six semi rectangular samples were taken from each strip, and so the overall number of samples used in this procedure was 36 samples. These 36 samples were divided into two categories (Annealed \& Cold Worked Samples) 18 samples for each category. One temperature $\left(750^{\circ} \mathrm{C}\right)$ was suggested to work for heat treatment for 1 hour; time was counted after 15 min to allow homogenizing the furnace atmosphere.

Carbolite furnace, model EML was used to anneal the samples. 9 samples were annealed for each run, for an hour; the same procedure was repeated for the other 9 samples \&so on. The 36 sample demonstrated formerly (18 Annealed \& 18 Cold worked) were prepared by grinding and polishing. All samples were cleaned by diluted hydrochloric acid, followed by acetone and Methanol to remove any impurities or scales that formed on the surface of the samples. The sample should be immersed in each solution for about 2 min and drying by air blower after each step.

A flat corrosion cell consist Reference electrode of $\mathrm{Ag}-\mathrm{AgCl}$ saturate was used to determine the corrosion rate. The exposed surface area of specimens was $0.78 \mathrm{~cm} 2$ in a medium of $\mathrm{NaCl}$ solution with different concentrations, namely, $1,2 \& 3.5 \%$ were used in this test. The potentiostat scan was operated using the same parameters for all samples and those were feed to the operating computer through the Princeton Applied research potentiostat wizard. The test was done at scan EI \& EV of 0.1 (v) vs. open circuit potential, IT, $1.0(\mathrm{~mA})$, and scan rate of 1.0 $\mathrm{mA} / \mathrm{s}$. In the rescan definition steps an equilibration for $30 \mathrm{sec}$ was adopted. And finally the IR compensation facility was enabled.

All samples were examined using scanning electron microscope. Electron micrographs were taken at different magnifications namely $12 \mathrm{X}, 100 \mathrm{X}$ and $600 \mathrm{X}$ before and after corrosion at different percentages of steel particles content. Vickers microhardness technique was used to measure the microhardness from matrix $(\mathrm{Cu})$ along through the reinforceing phase (Steel particle) under a predetermined load of $25 \mathrm{gf}$. The separation between each reading of microhardness $\&$ the other was $0.03 \mu \mathrm{m}$. 


\section{Results \& Discussion}

\subsection{Corrosion Rate of Composites:}

From Fig. (2) and Fig.(3) the increment in the solution concentration increases the corrosion rate; hence the conductivity of the solution is increased which provides more severity of chemical attack. The variation in corrosion rate in different concentrations is increased by increasing steel content; due to the availability of more active phase (steel) beside the increment in solution concentration both of which serves in favor of the increasing in corrosion rate.

Fig.(4), Fig.(5) \& Fig.(6) show that annealing decreases the corrosion rate especially when steel content is higher than $20 \mathrm{wt} \%$ of steel particles, which gives an indication for stress corrosion phenomenon in cold worked samples, since cold working produces high dislocation density this increases the stored energy of the metal which in its turn increases the corrosion rate as a consequence. Since annealing eliminates dislocations by annihilation, the annealed samples gave lower corrosion rate values. But what should be mentioned is that the variation of corrosion rate (the slope of each line) at the same heat treatment condition which is greater for the cold worked samples than the annealed ones. That is attributed to the fact that copper content becomes lower with the increment in steel volume fraction this leads to high dislocation density as a result (S.S. El-Egamy, 2008). That makes the difference in corrosion rate between $40 \mathrm{wt} \%$ sample and $30 \mathrm{wt} \%$ sample, in case of cold worked one, greater than in case of annealed.

The higher corrosion rate after $20 \mathrm{wt} \%$ for both deformed and annealed samples could be due to the fact that the density of $\mathrm{Fe}\left(7.86 \mathrm{~g} / \mathrm{Cm}^{3}\right)$ is smaller than that for $\mathrm{Cu}\left(8.96 \mathrm{~g} / \mathrm{Cm}^{3}\right)$ i.e. the volume fraction of steel particles (anode) becomes higher ( and then the area) than the corresponding volume fraction of $\mathrm{Cu}$ (cathode). This appears to be more clear with the volume fraction of $30 \mathrm{wt} \%$ and above. On the top of that the related total diffusion zone around the steel particles becomes larger; this effect leads to higher corrosion rate as well.

\subsection{Microstructure Examination of the Composites:}

From Fig. (7) the corrosion in copper-steel composite can be described as a selective corrosion behavior; since $\mathrm{Cu}$ is more noble than steel as a result the steel particles were corroded to a higher extent than copper matrix. This localized corrosion which is similar to pitting can be explained by the variation in the electro chemical potential of iron (the main component of steel) and copper, which means steel is more active than copper matrix, thus the steel particles are corroded selectively rather than the copper matrix. The difference in the density between steel and copper also affects the corrosion rate to be higher in the steel particles hence steel is of lower density than that of copper, so for a constant time of exposure to the corroding environment the steel particles will corrode faster than the copper matrix creating the localized pits (Feras M.A. Kafiah, 2007). And finally it should be mentioned that with increasing volume fraction of steel particles the severity of corrosion decreases in each particle and this can be seen in Fig.(8). That is due to the fixed number of ions in 3.5\% NaCl, which means that the internal corrosion current is constant as well. And so the corrosion current intensity for steel particles will be higher with small number of particles per unit area \& vice versa.

\subsection{Micro-hardness measurements.}

Fig. (9) Shows a scope of micro-hardness starting from the copper matrix through the diffusion area and finally to the core of the steel particle. From the figure the effect of heat treatment (annealing) was clear as expected i.e. hardness was lower by a certain margin indicating the decrement in dislocation density. This leads the corrosion rate to be lower than as cold worked ones. Another observation can be noticed from figure (9), namely, the variation in hardness values during moving from copper matrix to the steel particle (line slope between 0.12 $0.18 \mu \mathrm{m}$ ) is greater in cold worked sample than annealed one, which indicate that annealing enhances the diffusion process on one hand and limits the effect of stress corrosion on the formation of copper steel composite pits on the other hand (ASM Handbook. 2001)( P. Deshpande, J. H. Li, R. Y .Lin, 2005).

\section{Conclusions}

1) Corrosion rate of copper-steel composite increases with the increasing in steel particle content;

2) For corrosive environment applications the highest suitable steel particle content is $20 \mathrm{wt} \%$ for its low corrosion rate compared with the higher steel particle content.

3) Stress corrosion occurred in the composite when it was cold worked. Cold working affects the corrosion rate differently depending upon the volume fraction of steel particles.

4) Under uniform corrosive condition the corrosion reaction attacks the steel particle selectively rather than the copper matrix. 
5) The corrosion severity in steel particle decreases with the increasing steel particle content.

\section{References}

ASM Handbook.Vol.13. (2001). Corrosion", ASM International, Materials Park OH.

ASM Handbook.Vol.21. (2001). Composite, ASM International, Materials Park OH.

Feras M.A. Kafiah. (2007). preparation and characterization of copper- steel composite, MSc thesis, Dept. of Materials and Metallurgical Engineering- Al-Balqa Applied University, Al-Salt, Jordon.

Hatta, H., Aoi, T., Kawahara, I. and Kogo, Y. (2004). Tensile Strength of Carbon-Carbon Composites II. Effect of Heat Treatment Temperature for $\mathrm{C}-\mathrm{C}$ Reinforced with PAN-Based Fiber, Submitted for Pub. In J. Compos. Metal., 38(19):p.p 1685-1699.

P. Deshpande, J. H. Li, R. Y .Lin. (2005). Infrared Processed Cu/WC Composites, Materials Science and Engineering.

Pranav K. Deshpande. (2006). Wear Resistance and Electrical Property of Infrared Processed Copper/Tungsten Carbide Composites. A thesis submitted to the Department of Chemical and Materials Engineering, University of Cincinnati.

S.S. El-Egamy. (2008). Corrosion and corrosion inhibition of $\mathrm{Cu}-20 \% \mathrm{Fe}$ alloy in sodium chloride solution. Corrosion Science. 50 (928-937).

William D. Callister, Jr. (2007). Materials Science and Engineering An Introduction, 7Th Edition.

Z. J. Zhou, Y. S. Kwon. (2005). Fabrication of W-Cu Composite by Resistance Sintering Under Ultra-High Pressure, Journal of Materials Processing Technology, Vol. 168, pp. 107-111.

Table 1. Chemical composition of steel particles reinforcements

\begin{tabular}{|c|c|c|c|c|c|c|c|}
\hline $\begin{array}{c}\mathrm{Fe} \\
\mathrm{wt} \%\end{array}$ & $\begin{array}{c}\mathrm{C} \\
\mathrm{wt} \%\end{array}$ & $\begin{array}{c}\mathrm{Mn} \\
\mathrm{wt} \%\end{array}$ & $\begin{array}{c}\mathrm{Al} \\
\mathrm{wt} \%\end{array}$ & $\begin{array}{c}\mathrm{Si} \\
\mathrm{wt} \%\end{array}$ & $\begin{array}{c}\mathrm{P} \\
\mathrm{wt} \%\end{array}$ & $\begin{array}{c}\mathrm{S} \\
\mathrm{wt} \%\end{array}$ & $\begin{array}{c}\mathrm{Cr} \\
\mathrm{wt} \%\end{array}$ \\
\hline 98.95 & 0.45 & 0.2 & 0.1 & 0.1 & 0.05 & 0.05 & 0.1 \\
\hline
\end{tabular}

Table 2. Casts weight Details

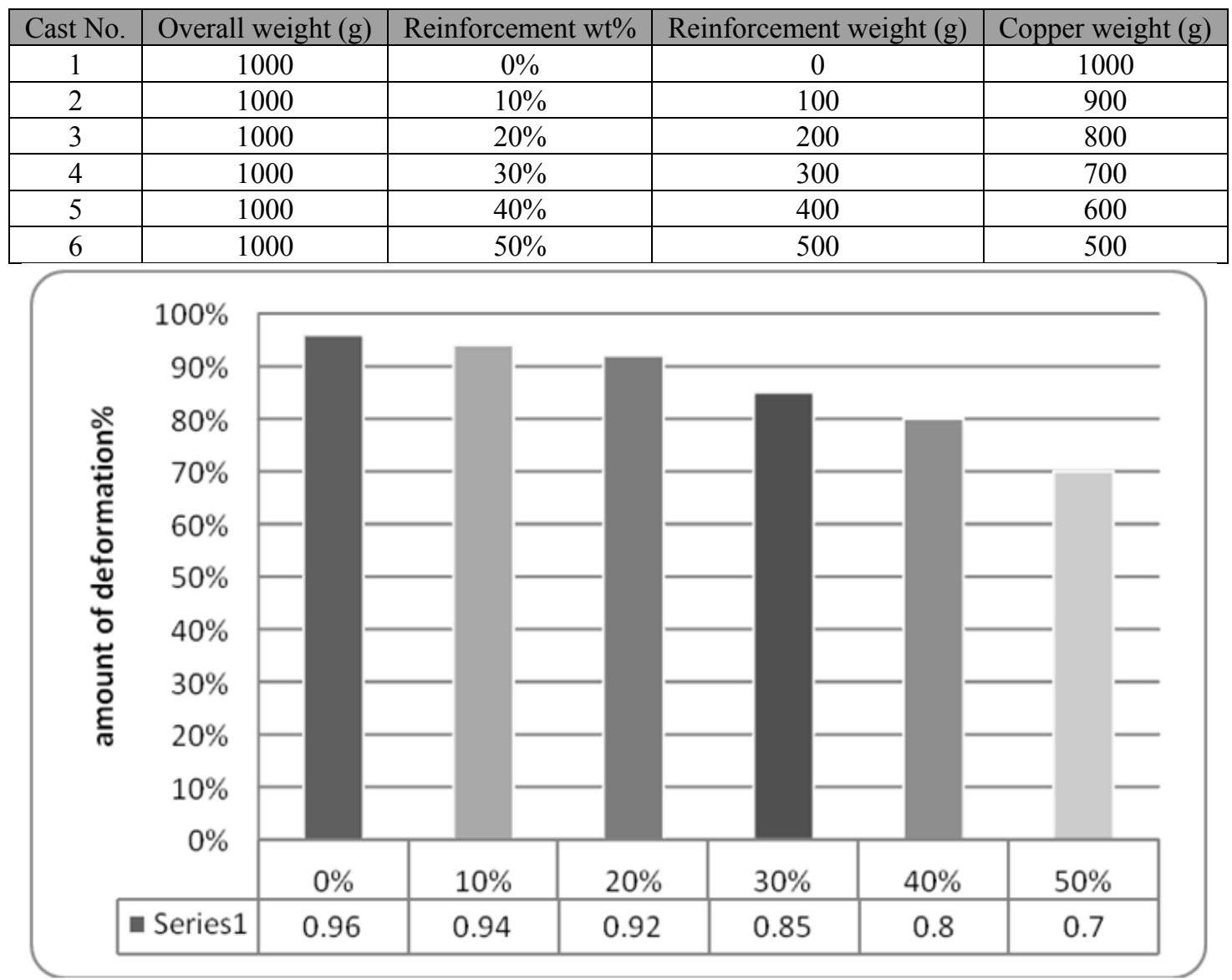

Figure 1. Deformability versus $w t \%$ of steel particles 


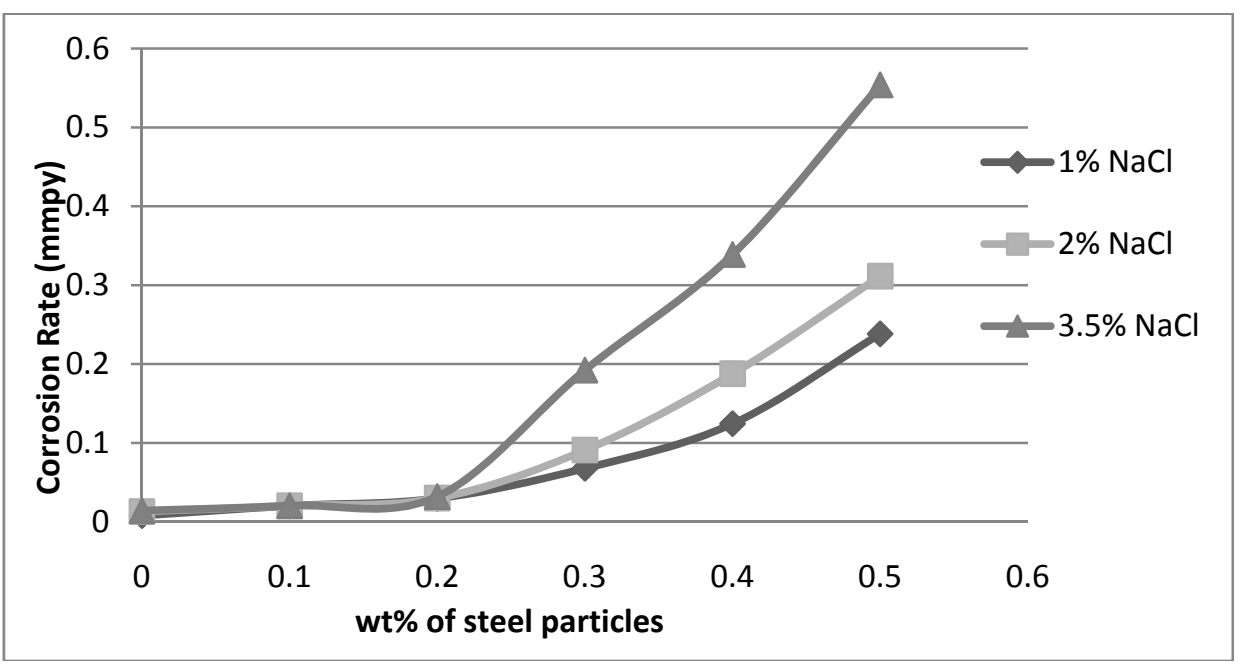

Figure 2. Corrosion rate at different concentration of $\mathrm{NaCl}$ for cold worked samples

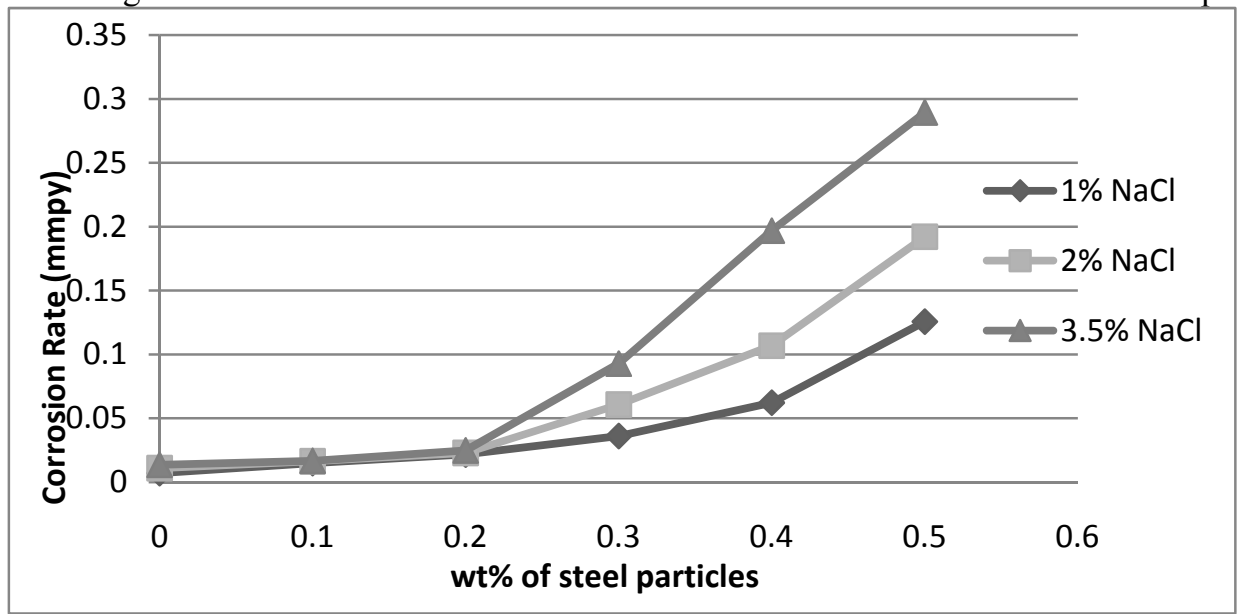

Figure 3. Corrosion rate at different concentration of $\mathrm{NaCl}$ for annealed samples

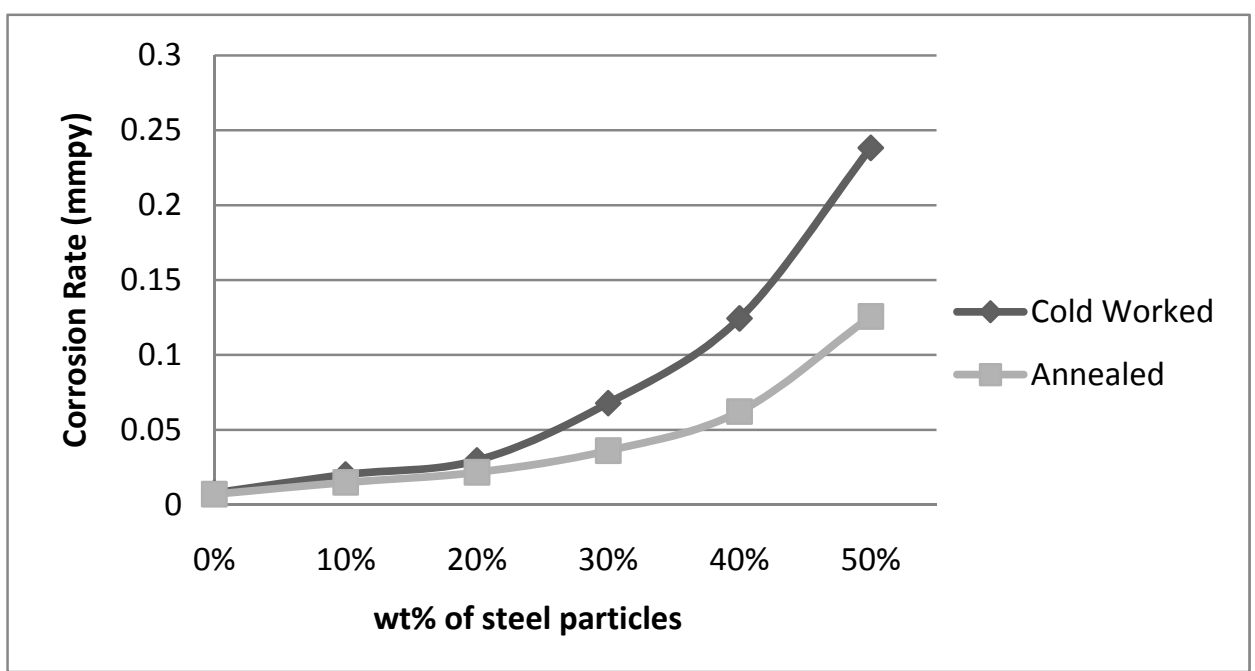

Figure 4. Cold Worked \& Annealed Samples at $1 \% \mathrm{NaCl}$ 


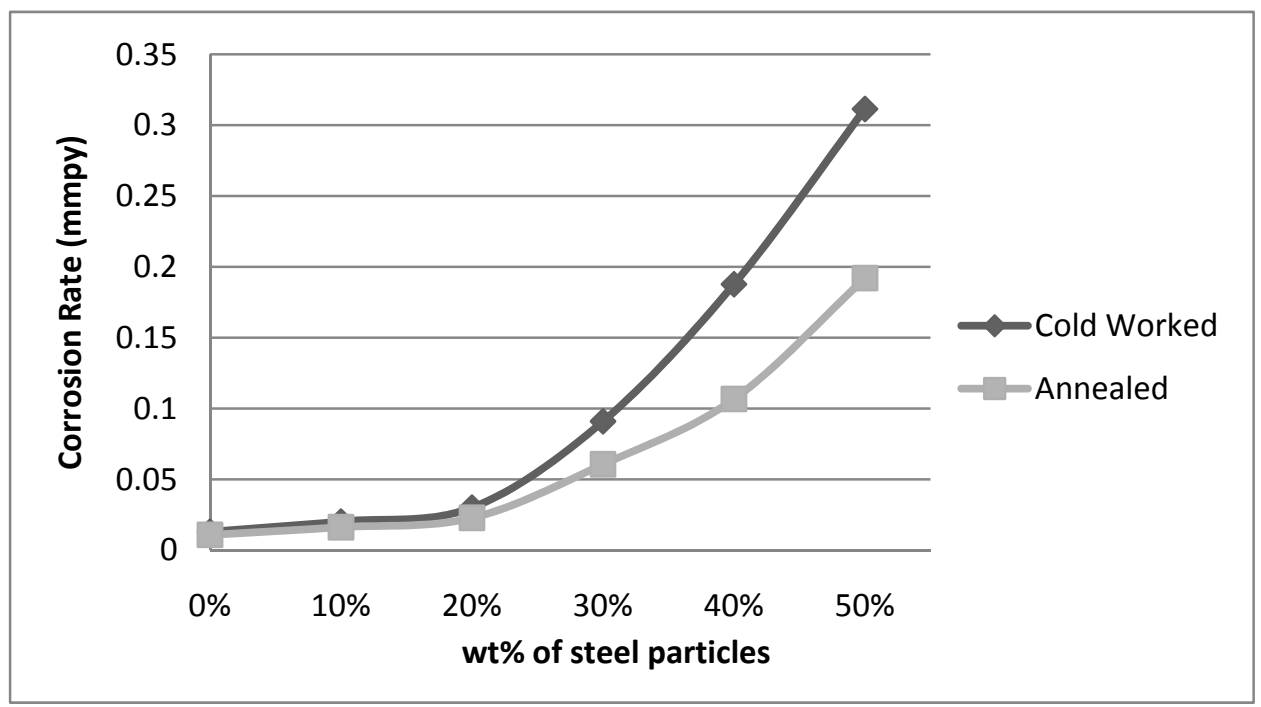

Figure 5. Cold Worked \& Annealed Samples at 2\% $\mathrm{NaCl}$

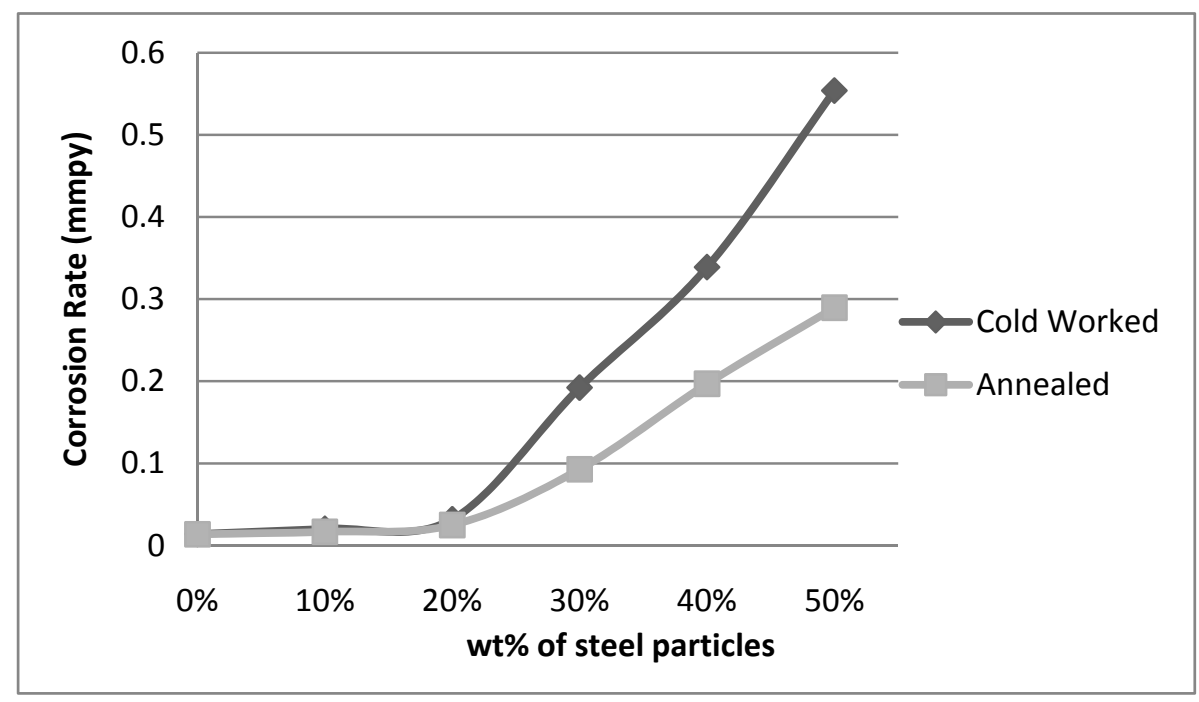

Figure 6. Cold Worked \& Annealed Samples at 3.5\% NaCl

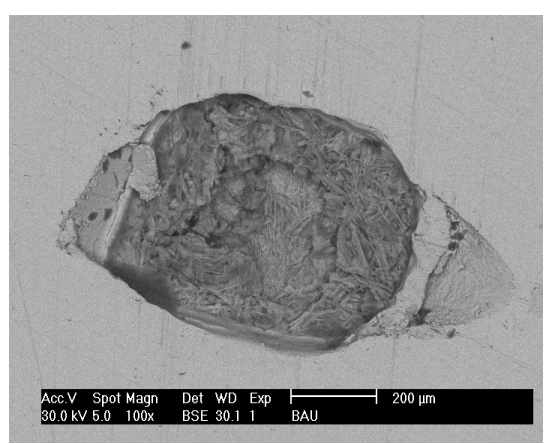

(a)

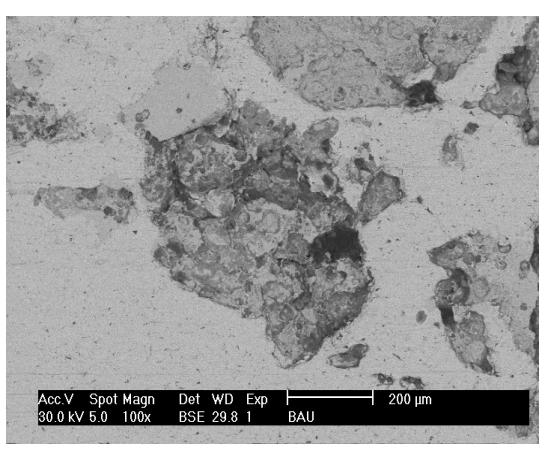

(b) 


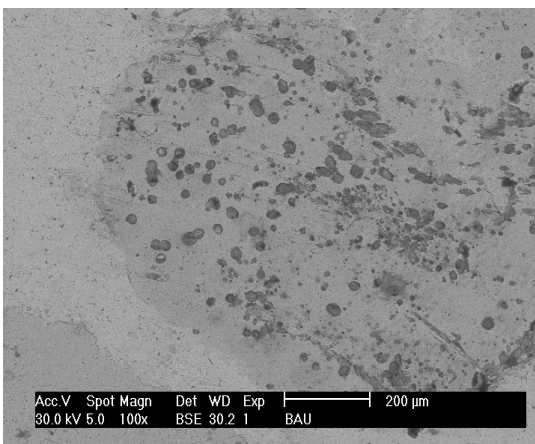

(c)

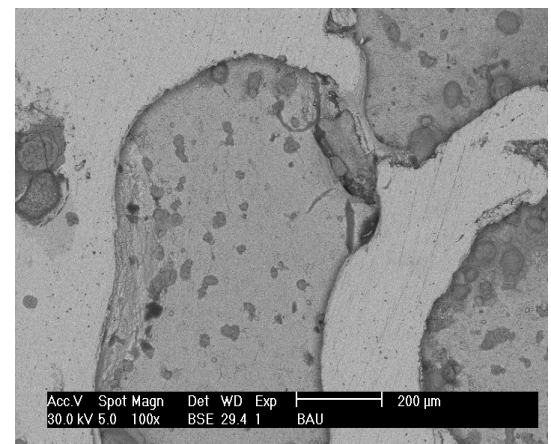

(d)

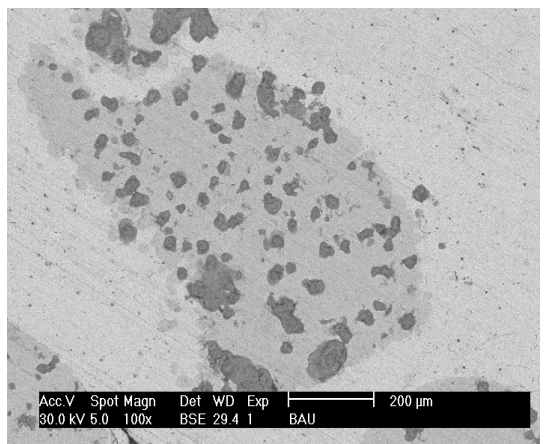

(e)

Figure 7. Scanning electron microscopy images show steel particles after corrosion in $3.5 \% \mathrm{NaCl}$ solution at different weight percent of steel particles in Cu-matrix, (a) $10 \mathrm{wt} \%$, (b) $20 \mathrm{wt} \%$, (c) $30 \mathrm{wt} \%$, (d) $40 \mathrm{wt} \%$ and (e) $50 \mathrm{wt} \%$

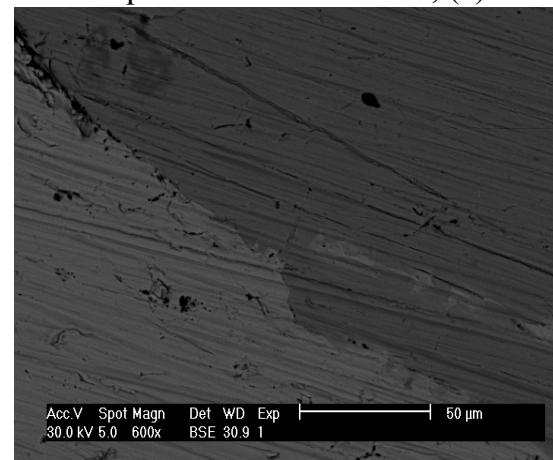

Before

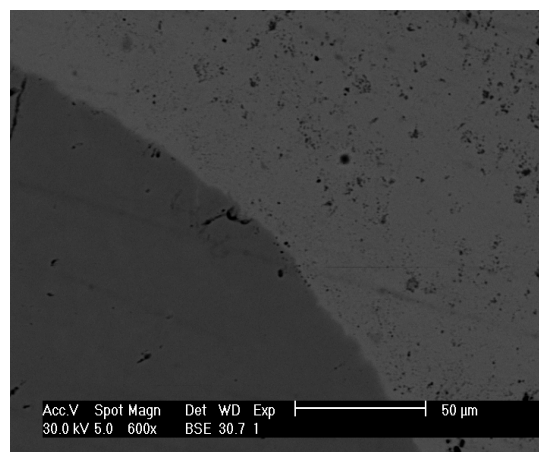

Before

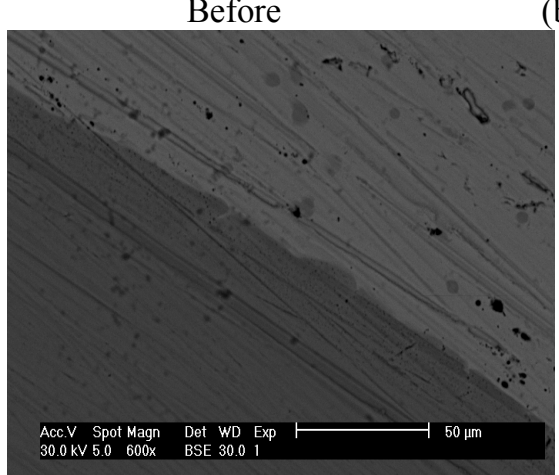

Before

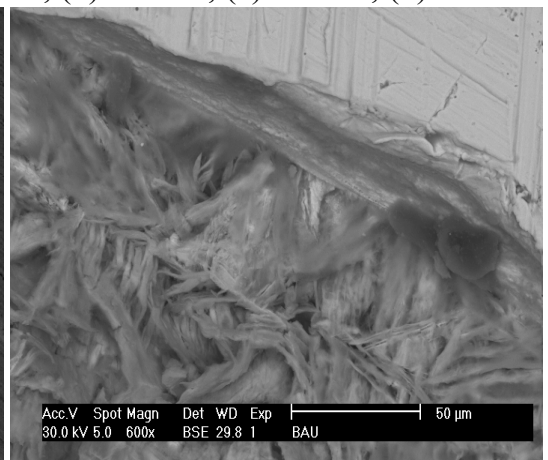

(a)

After

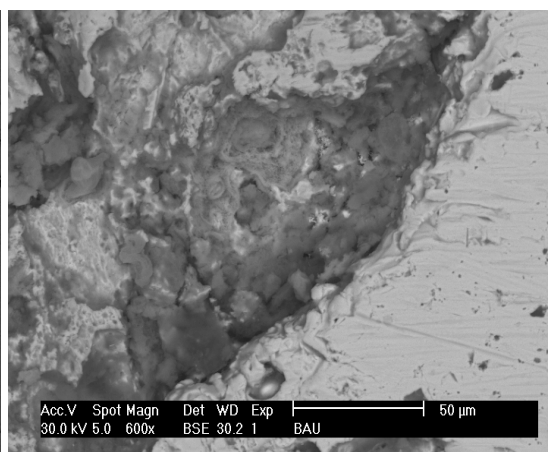

(b)

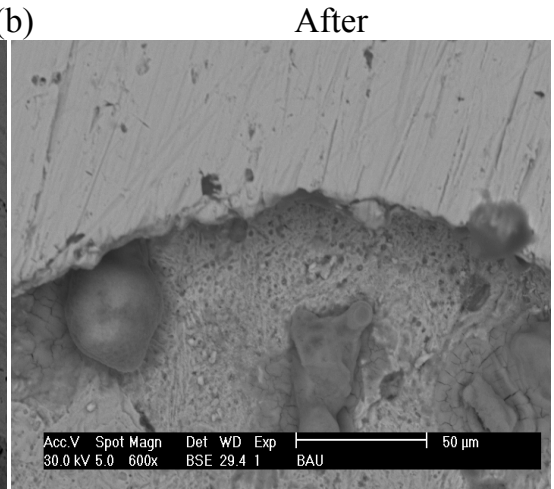

(c)

After

Figure 8. Scanning electron microscope images show steel particles before and after corrosion in $3.5 \% \mathrm{NaCl}$ solution at different weight percent of steel particles in Cu-matrix, (a) $10 \mathrm{wt} \%$, (b) $20 \mathrm{wt} \%$, and (c) $30 \mathrm{wt} \%$ 


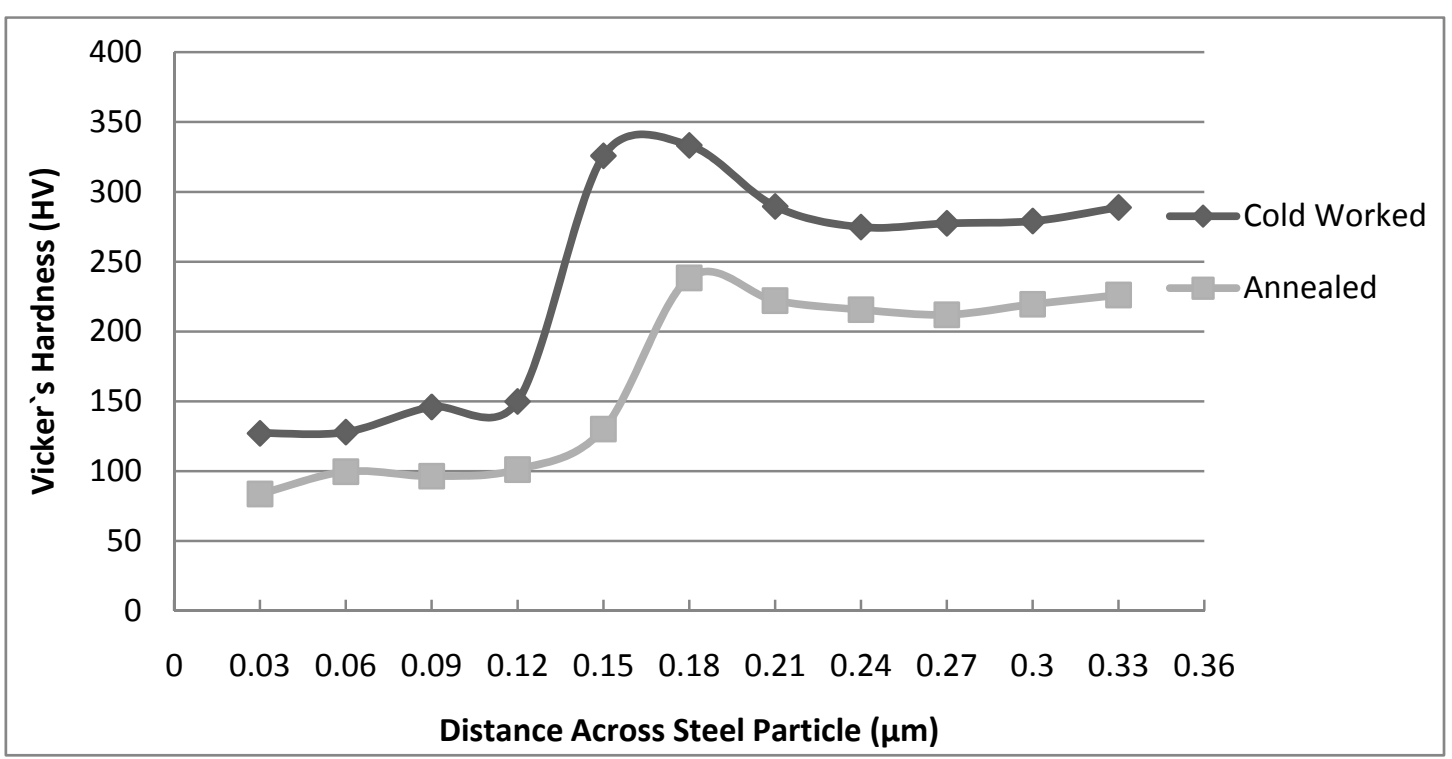

Figure 9. Vickers micro-hardness (HV) across the steel particle and the copper matrix 